\title{
STRESS DISTRIBUTION IN THE ADHESIVE JOINT OF A "SANDWICH" SPECIMEN
}

\begin{abstract}
Jasińska A.*, Ligaj B.**
Abstract: The paper presents numerical calculations results of a sandwich specimen subjected to four-point bending. The sample was loaded with a bending moment of $\mathrm{Mg}=16 \mathrm{Nm}$. The specimen was made of the following materials: upper beam M1 - structural steel S235JR, lower beam M2 - aluminum alloy AW-2017A, glued joints AJ - MULTIBOND-3670 adhesive. The purpose of the paper is to present the stress distribution in glued joints of the sandwich type sample under four-point bending. The variable value in the calculations was the glued joint shape of the side surface. As a result of calculations, reduced stress distributions in glued joints were determined, which showed that: the highest stress values $\sigma_{H-M}$ occur in glued joint AJ with flat side surfaces at the contact with the upper beam M1 in its central (point GZ_2), on the glued joint inner surface AJ with flat side surfaces obtained a different stress distribution than on the outer surface of this joint.
\end{abstract}

Keywords: Glued joint, Sandwich type specimen, Stress distribution, Bending moment, FEM calculations.

\section{Introduction}

Gluing is a joining method that is increasingly common in many areas of technology where other joining methods cannot or should not be used, e.g., for practical or visual reasons (Adams et al., 1984). These include the combination of various materials (e.g. metal and polymeric materials), integration of additional functions (e.g. watertightness, damping, thermal conductivity or separation), preservation of material properties (e.g. prevention of distortion), improvement of component properties (e.g. lightweight construction, fixing reinforcements) and surface treatment (e.g. design with adaptation of veneers). The glued joints strength and durability have proper preparation of joined surfaces, which are prepared in industrial conditions by available technologies, i.e. turning (Mikołajczyk et al., 2016), grouting (Musiał et al., 2018) etc.

The method of gluing is widely used: in the machine industry, in the construction of medical instruments and tools (Wirwicki et al., 2017), in means of transport, etc. Examples are rail vehicles, buses, in which gluing allows: combining various materials, compensation of construction errors, reducing vehicle weight, shortening production time (Ligaj et al., 2018). Structural adhesives: epoxy, acrylic and polyurethane.

Glued joints experimental tests are carried out on samples of dimensions specified in relevant standards. The assessment of the glued joint strength carried out in laboratory conditions is to provide information necessary for the proper selection of the connection geometrical features. The glued joints strength tests can be carried out using samples of the shape shown in Fig. 1. The specimen construction was submitted as an invention to the Patent Office of the Republic of Poland, in which it was registered under the number P.422884 (Ligaj et al., 2017).

The test specimen (Fig. 1) consists of: upper beam (M1), lower beam (M2), two glued joints (AJ) and strain gauges $(\mathrm{T}())$. Glued joints $(\mathrm{AJ})$ are located symmetrically relative to the long edge of the upper beam (M1). The lower beam (M2) is located symmetrically in relation to the M1 beam and AJ joints. On

\footnotetext{
* PhD. student Anna Jasińska: Faculty of Mechanical Engineering, UTP University of Science and Technology in Bydgoszczy, al. Prof. S. Kaliskiego 7, 85-796 Bydgoszcz, PL, jasinska.an@wp.pl

** Prof. Bogdan Ligaj, PhD.: Faculty of Mechanical Engineering, UTP University of Science and Technology in Bydgoszczy, al. Prof. S. Kaliskiego 7, 85-796 Bydgoszcz, PL, bogdan.ligaj@utp.edu.pl
} 
the M1 beam and M2 beam, measuring points (S ()) were determined where deformation is measured at the time of testing. In the sample symmetry axis (between the glued joints) there are measuring points: S2 on the M1 beam and S3 on the M2 beam. The measuring point S1 located on the M1 beam is outside the AJ connectors. At each measuring point S1, S2 and S3 two strain gauges (T ()) were placed, located on both sides of the beam. The sample is intended to assess the glued joints strength under the controlled deformation conditions of machine structural elements. The most favorable sample form loading is fourpoint bending with monotonically increasing bending moment value. During testing, the specimen rests on supports A spaced by $\mathrm{X}$ value. Forces loading the sample are applied at points $\mathrm{B}$, spaced by $\mathrm{Y}$ value (Jasinska et al., 2018).

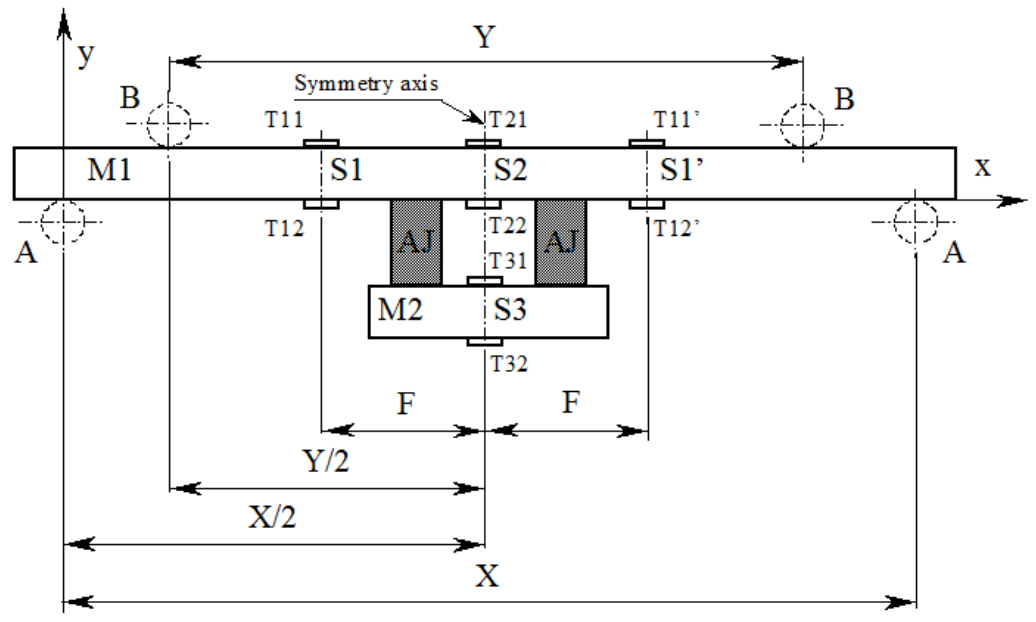

Fig. 1: The sandwich sample and its loading method during tests (Jasinska et al., 2018).

The aim of the work is to present the stress distribution in glued joints of the sandwich sample under 4-point bending. The variable value in the calculations was the side surface shape of the glued joint.

\section{Numerical calculations}

\subsection{Specimen dimensions and calculation conditions}

Calculations were carried out under four-point bending (Fig. 2). The places where the load is applied are located at the following distances: $\mathrm{L} 1=360 \mathrm{~mm}, \mathrm{~L} 2=180 \mathrm{~mm}$. The value of bending moment $\mathrm{Mg}=16 \mathrm{Nm}$. The upper beam M1 was made of S235JR structural steel: $\mathrm{S}_{\mathrm{y}}=235 \mathrm{MPa}, \mathrm{E}=2.1 .10^{5} \mathrm{MPa}$, $v=0.30$. The lower beam M2 was made of aluminum alloy AW-2017A: $\mathrm{S}_{\mathrm{y}}=317 \mathrm{MPa}, \mathrm{E}=73077 \mathrm{MPa}$, $v=0.33$. Glued joints AJ are made of MULTIBOND - 3670 glue (according to the manufacturer): $\mathrm{S}_{\mathrm{u}}=22 \mathrm{MPa}, \mathrm{E}=2780 \mathrm{MPa}, v=0.40, \mathrm{~A}=\sim 15 \%$.

The calculations were carried out in ABAQUS 6.6-4. o discretize the 3D models presented above, threedimensional finite elements of the C3D4H type were taken from the library of the ABAQUS 6.6-4 program.

a)

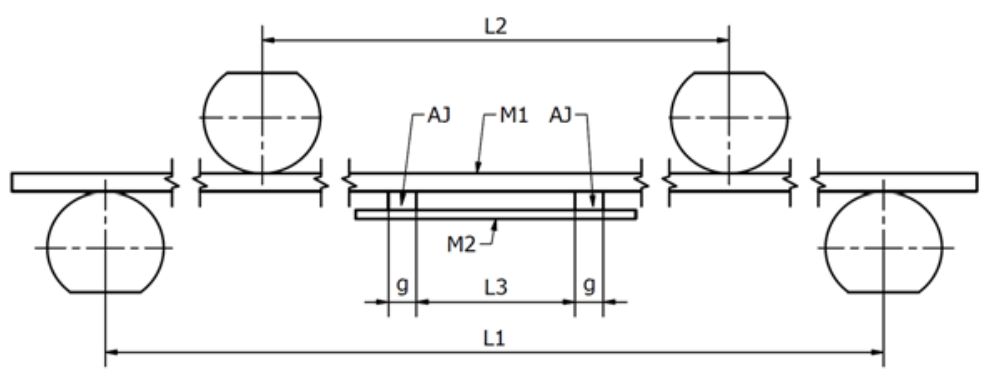

b)

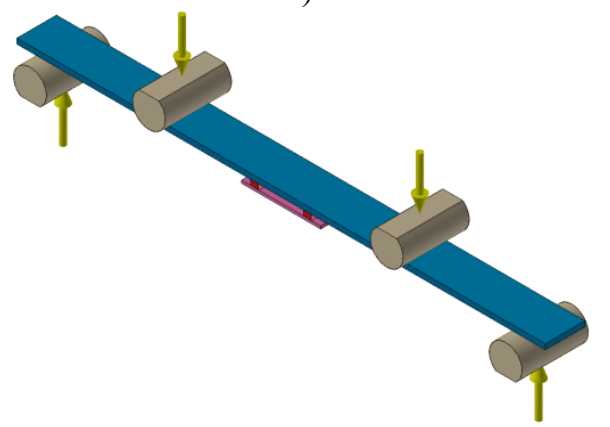

Fig. 2: General form of the sandwich specimen used in the calculations: a) specimen dimensions; b) bending moment loading method.

The dimensions of the specimen used in the numerical calculations are shown in Fig. 3. 
a)

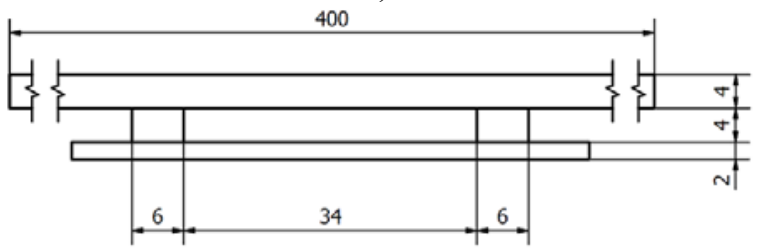

b)

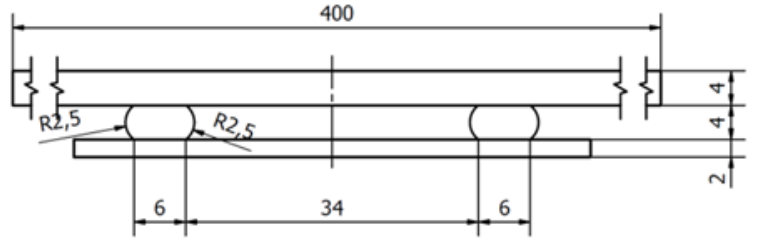

c)

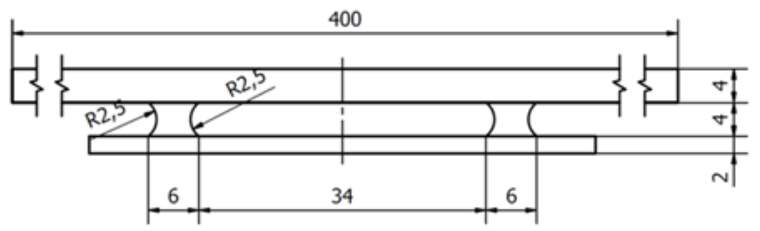

d)

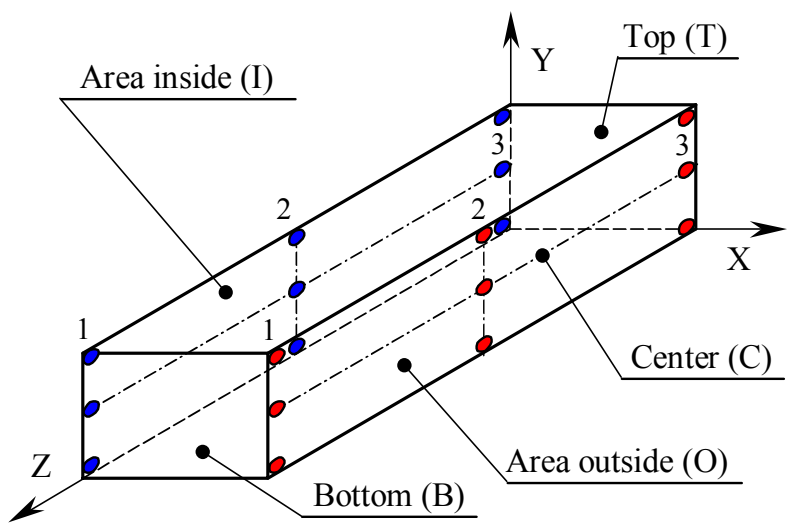

Fig. 3: Dimensions of the sandwich sample used in the calculation: a) with flat side surfaces of the glued joint; b) with convex side surfaces of the glued joint; $c$ ) with concave side surfaces of the glued joint;

d) determination of stress reading points.

\subsection{Numerical calculations results}

Figs. $4 \div 6$ show the stress distributions in the fragments of the sandwich specimen including glued joints.

a)

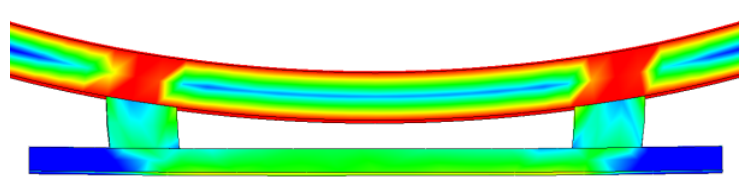

b)

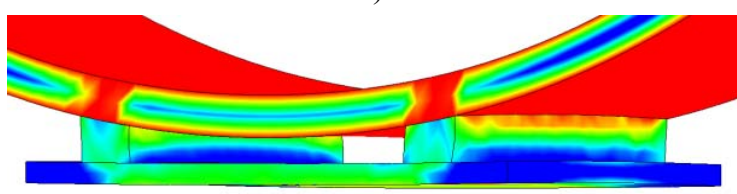

Fig. 4: Huber-Mises reduced stress in a glued joint with flat side surfaces [MPa]: a) side view;

b) axonometric view.

a)

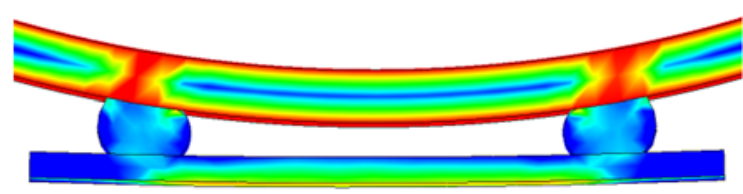

b)

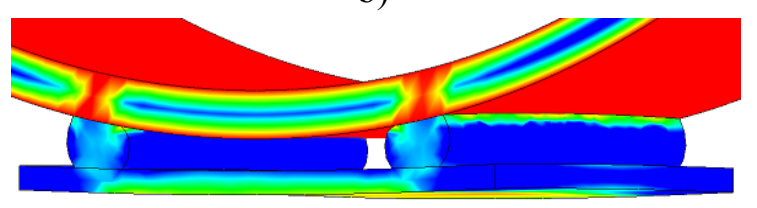

Fig. 5: Huber-Mises reduced stress in a glued joint with convex lateral surfaces [MPa]: a) side view; b) axonometric view.

a)

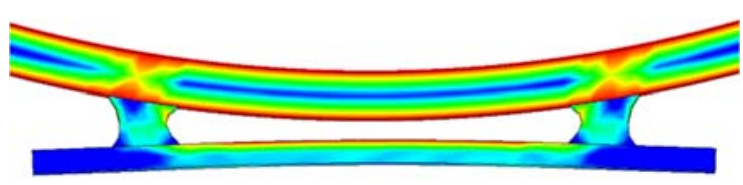

b)

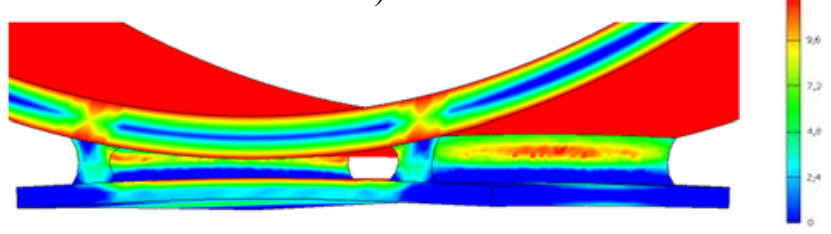

Fig. 6: Huber-Mises reduced stress in a glued joint with concave side surfaces [MPa]: a) side view; b) axonometric view

The stresses values at individual points of the glued joint are presented in Tab. 1. The results were read according to the diagram in Fig. 3d, i.e. on the lateral (external and internal) surface of the right glued joint. 
Tab. 1: Huber-Mises reduced stress $\sigma_{H-M}$ in MPa.

\begin{tabular}{|c|c|c|c|c|c|c|c|}
\hline \multirow{2}{*}{$\begin{array}{l}\text { Stress } \\
\text { reading } \\
\text { location }\end{array}$} & \multicolumn{3}{|c|}{ The weld side surface shape } & \multirow{2}{*}{$\begin{array}{l}\text { Stress } \\
\text { reading } \\
\text { location }\end{array}$} & \multicolumn{3}{|c|}{ The weld side surface shape } \\
\hline & Flat & Convex & Concave & & Flat & Convex & Concave \\
\hline TO 1 & 11 & 8 & 5 & TI 1 & 11 & 12 & 5 \\
\hline TO 2 & 14 & 14 & 8 & TI 2 & 10 & 9 & 4 \\
\hline $\mathrm{TO} 3$ & 10 & 8 & 5 & TI 3 & 11 & 12 & 5 \\
\hline $\mathrm{CO} 1$ & 7 & 1 & 5 & CI 1 & 8 & 1 & 8 \\
\hline $\mathrm{CO} 2$ & 8 & 1 & 11 & CI_2 & 7 & 1 & 8 \\
\hline $\mathrm{CO} \_3$ & 7 & 1 & 6 & CI_3 & 8 & 1 & 9 \\
\hline $\mathrm{BO} \_1$ & 6 & 5 & 2 & BI_1 & 4 & 3 & 1 \\
\hline $\mathrm{BO} \_2$ & 2 & 3 & 1 & BI_2 & 2 & 3 & 1 \\
\hline $\mathrm{BO} \_3$ & 6 & 5 & 2 & BI_3 & 4 & 3 & 1 \\
\hline
\end{tabular}

\section{Analysis of tests results and conclusions}

Based on the stress distributions in the glued joints of the sandwich sample, it was observed that:

a) the highest stress values $\sigma_{\mathrm{H}-\mathrm{M}}$ occur in glued joint $\mathrm{AJ}$ with flat side surfaces at the contact with the upper beam M1 in its central part (point TO_2),

b) at the contact of the glued joint $\mathrm{AJ}$ with the bottom beam $\mathrm{M} 2$ the highest stress value $\sigma_{\mathrm{H}-\mathrm{M}}$ at the joint edges (points BO_1 i BO_3), and its value is about $50 \%$ of the stress value at points TO_1 and TO_3,

c) in the central part of the AJ joint on the outer surface, the highest stresses $\sigma_{\mathrm{H}-\mathrm{M}}$ were obtained at point CO_2,

d) on the internal surface of the glued joint AJ with flat side surfaces a different stress distribution was obtained than on the external surface of this joint; on the inner surface of the joint, the highest stresses $\sigma_{\mathrm{H}-\mathrm{M}}$ were on its edges,

e) stress distribution in glued joints $\mathrm{AJ}$ with convex side surfaces at the point of connection with the upper beam M1 is similar to the distribution in joint AJ with the flat side surfaces, in the joint AJ center part on the external and internal surfaces the value is similar low,

f) the highest stress values $\sigma_{\mathrm{H}-\mathrm{M}}$ in glued joint $\mathrm{AJ}$ with concave side surfaces occur in the middle of its part on external surface at point $\mathrm{CO}_{-} 2$.

\section{References}

Adams, R. D., Wake, W. C. (1984) Structural Adhesive Joints in Engineering, Elsevier, London.

Jasinska, A., Ligaj, B., Mazurkiewicz, A. (2018) Experimental studies of adhesive joints in four-point static bending, IOP Conference Series: Materials Science and Engineering, vol. 393, iss. 1, Article no. 012032.

Jasinska, A., Ligaj, B., Miciak, M. (2018) The method of diagnosing glued joints subjected to static loads, MATEC Web of Conferences, vol. 182, Article no. 01002.

Ligaj, B., Jasińska, A., Karolewska, K. (2017) Patent application no. P.422884, Test specimen for bonding materials with significantly different physical properties, especially steel-glass, Polish Patent Office.

Ligaj, B., Wirwicki, M., Karolewska, K., Jasinska, A. (2018) Experimental studies of glued Aluminum-glass joints, 3rd International Conference on Science, Technology, and Interdisciplinary Research (IC-Star), Book Series: IOP Conference Series-Materials Science and Engineering, vol. 344, no. UNSP 012014, doi: 10.1088/1757$899 \mathrm{X} / 344 / 1 / 012014$.

Mikołajczyk, T., Fąs, T., Kłodowski, A., Matuszewski, M., Olaru, A., Olaru, S. (2016) Computer Aided System for Superfinishing Process Control. Proceedings $9^{\text {th }}$ International Conference Interdisciplinarity in Engineering, INTER-ENG 2015, Book Series: Procedia Technology, vol. 22, pp. 48-54.

Musiał, J., Polasik, R., Kałaczyński, T., Szczutkowski, M., Łukasiewicz, M. (2018) Milling efficiency aspects during machining of 7075 aluminium alloy with reference to the surface geometrical structure. $24^{\text {th }}$ International Conference on Engineering Mechanics, Engineering Mechanics vol. 24, pp. 569-572.

Wirwicki, M., Andryszczyk, M., Andrzejewska, A., Topolinski, T. (2017) Testing the strength of the adhesive connection in specimen - monotonic tensile and shear with under variable load, Engineering Mechanics, Book Series: Engineering Mechanics, pp. 1054-1057. 